\title{
Human and machine: Evaluating whether action automation influences visual perception
}

\author{
Nathan L. Tenhundfeld ${ }^{1}$. Jessica K. Witt ${ }^{2}$ \\ Published online: 29 April 2020 \\ (C) The Psychonomic Society, Inc. 2020
}

\begin{abstract}
The action-specific account of perception suggests that our perceptual system is influenced by information about our ability to act in our environment and, thus, affects our perception. However, the specific information about action that is influential for perception is still largely unknown. For example, if a goal is achieved through automation rather than action, is perception influenced because the goal was achieved or is perception immune because the act was automated rather than performed by the observer? In four experiments, we examined whether automating a paddle to block a moving ball in a computer game similar to Pong affects perception of the ball's speed. Results indicate that the automation used here did not affect speed perception of the target. Whereas tools such as reach-extending sticks and various-sized paddles are both incorporated into one's body schema and also influence spatial perception, automation, our results imply that automation is not incorporated into one's body schema and does not affect spatial perception. The dissociation in how the mind treats tools versus automation could have several implications as automation becomes more prevalent in daily life.
\end{abstract}

Keywords Perception and Action · Visual perception

The action-specific account of perception suggests that our perceptual system is affected by the capabilities of the body when perceiving our surrounding environment (Proffitt, 2006; Witt, 2011a). This account represents a significant departure from other theories of perception because it emphasizes action as a source of information for perception, rather than exclusively the end goal. For example, individuals tend to report seeing distances on a hill as being farther than distances on the flat ground (Laitin, Tymoski, Tenhundfeld, \& Witt, 2019; Stefanucci, Proffitt, Banton, \& Epstein, 2005; Tenhundfeld \& Witt, 2017), and softball players who are hitting better report seeing the softball as larger than do those who are not hitting as well (Gray, 2013; Witt \& Proffitt, 2005).

As it relates to perception, the action-specific account of perception says that the brain does not simply process only visual stimuli during visual perception. Nonvisual information includes the body's capabilities, opportunities for action, and the individual's overarching intentions (Proffitt, 2006). In the

Nathan L. Tenhundfeld

nlt0006@uah.edu

1 Department of Psychology, University of Alabama in Huntsville, Huntsville, AL, USA

2 Department of Psychology, Colorado State University, Fort Collins, CO, USA above softball example, the claim is that the player's brain is affected by information about her ability to hit the softball during her perception of the softball. For evidence that information influenced perception, changes in capabilities, opportunities for action, or intention must elicit corresponding changes in an individual's percept. Conversely, if there is a change in capabilities, opportunities for action, or intention without a corresponding perceptual change, then we can say that the information is not deemed relevant by the perceptual system and thus does not influence the percept.

These sorts of action-specific effects have been found in direct manipulations of action capabilities. When reaching with a stick, objects that were otherwise out of reach look closer than they do when reaching without the stick (Witt, 2011a; Witt, Proffitt, \& Epstein, 2005). Similarly, when using flippers, swimmers see underwater targets as being closer than when they are unaided by the flippers (Witt, Schuck, \& Taylor, 2011), and archers using an arm stabilizer perceive the target to be bigger than they do when not using the stabilizer (Y. Lee, Lee, Carello, \& Turvey, 2012). These effects also exist in virtual environments. Changing an individual's body size in a virtual environment affected egocentric distance estimates (Leyrer, Linkenaugery, Bülthoffz, Kloosx, \& Mohler, 2011), and changing the size of a virtual paddle used to block a ball affects perceptions of speed (Witt \& Sugovic, 2010). Even cars seem to affect perception; when driving, distances look 
shorter than they do when walking (Moeller, Zoppke, \& Frings, 2016).

With all of that, the question remains about what information about action does and does not influence perception. Research has suggested that tools (Moeller et al., 2016; Witt, 2011a; Witt et al., 2005), performance (Carsten, Lai, Barnard, Jamson, \& Merat, 2012; King, Tenhundfeld, \& Witt, 2017; Y. Lee et al., 2012; Witt \& Dorsch, 2009; Witt \& Sugovic, 2010), energetics (Eves, Thorpe, Lewis, \& Taylor-Covill, 2014; Stefanucci et al., 2005; Tenhundfeld \& Witt, 2015, 2017), and even things like fear (Stefanucci, Proffitt, Clore, \& Parekh, 2008; Witt \& Sugovic, 2013) can all affect perception. Other research has suggested that things like body size (Firestone \& Scholl, 2014) and energetics (Durgin et al., 2009; Durgin, Klein, Spiegal, Strawser, \& Williams, 2012) are not relevant for perceptual processes and instead affect postperceptual processes such as those involved in generating the response.

One avenue that has yet to be directly explored pertains to the use of automation. Broadly, we are using Parasuraman, Sheridan, and Wicken's (2000) definition of automation as "a device or system that accomplishes (partially or fully) a function that was previously, or conceivably could be, carried out (partially or fully) by a human operator, page 477." These functions are proposed automatable equivalents of the four-stage model of human information processing of filtering, assessment, decision, and action execution (Onnasch, Wickens, Li, \& Manzey, 2014; Sebok \& Wickens, 2017; Sternberg, 1969; Table 1). While we tend to think of automation as representing cutting-edge technology, such as that found in self-driving vehicles (e.g., Tenhundfeld et al., 2019; Tomzcak et al., 2019), the reality is that many users interact with automated technologies regularly. For example, cruise control, dishwashers, motionactivated doors, and elevators all represent forms of automation. The question, however, is how automation of the aforementioned action execution stage affects perception.

In addition to the stages that can be automated, there are varying levels of the automation itself. There are several frameworks with which to conceptualize the levels (Onnasch et al., 2014; Sheridan \& Verplank, 1978; Society for Automotive Engineers, 2018). Each of these frameworks consider a range from no automation (in which the human performs the task entirely) to full autonomy (in which the machine performs the task entirely, without the need for any human input or supervision).

While not framed as such, Moeller et al.'s (2016) evaluation of driving's effect on perception was an evaluation of automation's effect on perception. Because a vehicle (which is an automated system) allows the driver to traverse a given distance with less energy expenditure than walking, the driver's perceptual system seems to be influenced by this automated aid. However, in that study, the participant still was required to choose (Stage 3) to initiate the action (Stage 4; Onnasch et al., 2014). This seems to signify that a low level of automation at a late stage may influence users' perception. It is not known, however, what happens when the decision to act is not made by the user, or when there is no action required from the user.

On the one hand, perhaps an automated technology is treated like a tool by the perceptual system. In this case, changes in performance with the automation would result in corresponding changes in percept. This would be analogous to the stick in Witt et al. (2005). On the other hand, perhaps automated technologies do not influence perceptual processes unless the user plays some direct role in the action, whether that be the selection or the implementation of the action, at later stages and lower levels of automation. Understanding this role of automation in action-specific perception will help researchers better understand the nature of perception. Namely, what are the necessary components for information to be deemed relevant, and thus incorporated into one's body schema in such a way that it affects spatial perception? Additionally, results could have important impacts on the design of automated systems in which the human user may be required to regain control at any point (e.g., Barnes, Elliott, Wright, Scharine, \& Chen, 2019; de Visser, Cohen, Freedy, \& Parasuraman, 2014; J. D. Lee \& See, 2004; Miller \& Parasuraman, 2007).

In four studies, we evaluated whether an automated system can affect perception. To do so, we used the Pong task (King et al., 2017; Witt \& Sugovic, 2010; Witt, Sugovic, Tenhundfeld, \& King, 2016). In the Pong task, participants use a virtual paddle to block a virtual ball as it moves across the screen, then estimate the speed of the ball. The task of

Table 1 Automation stages (adapted from Onnasch et al., 2014)

\begin{tabular}{|c|c|}
\hline Automation stage & Description \\
\hline $\begin{array}{l}\text { Information acquisition } \\
\text { (filtering) }\end{array}$ & Collection of information from the environment \\
\hline $\begin{array}{l}\text { Information analysis } \\
\text { (integration) }\end{array}$ & Integrating the information together in order to inform a decision \\
\hline $\begin{array}{l}\text { Action selection } \\
\text { (decision) }\end{array}$ & Deciding which action to perform based on the integrated information \\
\hline $\begin{array}{l}\text { Action implementation } \\
\text { (implement) }\end{array}$ & Carrying out the desired action \\
\hline
\end{tabular}


blocking the ball is made easier by rendering the paddle as bigger, or made harder by rendering the paddle as smaller. The typical finding is that the ball is judged to be faster when the paddle is smaller, and thus blocking the ball is more difficult than when the paddle is bigger. This difference in perceived ball speed across the two paddle sizes is known as the Pong effect.

We opted to use the Pong task because a substantial amount of evidence has explored whether the Pong effect reflects a genuine difference in perception or an alternative explanation. Alternative explanations include response bias, judgmentbased effects, memory-based effects, and preperceptual processes such as attention (Cooper, Sterling, Bacon, \& Bridgeman, 2012; Durgin et al., 2009; Durgin et al., 2012; Firestone, 2013; Firestone \& Scholl, 2014; Wesp, Cichello, Gracia, \& Davis, 2004; Wood, Vine, \& Wilson, 2013). All of these alternatives have been explored regarding the Pong effect (King et al., 2017; Witt et al., 2016; Witt, Tenhundfeld, \& Bielak, 2017; Witt, Tenhundfeld, \& Tymoski, 2018). This work was summarized in Witt (2017) and will not be repeated here.

To investigate whether an automated technology can affect perception, the paddle was automated, meaning that it controlled its own movements as it attempted to block the ball. If this version of automation is relevant to the perceptual system, the ball should look slower when the automated paddle' performance is successful. To preview our results: This form of automation did not affect perceived ball speed, and thus does not seem to affect one's potential for action in a way that influences perception. Perceived speed was independent of the paddle's performance when the paddle was automated. However, when participants were required to act to engage the automation, the perceiver's own anticipated ability (rather than the automated paddle's performance) affected their perception: They perceived ball speed as if they were controlling the paddle themselves, even though it was automated. Combined, the results suggest that the perceptual system essentially ignores information about automation. When no action was required, perception was a function of visual information. When action was required at the start of the trial, perception was also influenced by anticipated abilities as if there were no automation. Thus, the perceptual system, which can be influenced by tools, does not seem to be influenced by this form of automation.

\section{Experiment 1}

\section{Method}

Participants We recruited 30 undergraduates from the available research pool at Colorado State University. The Pong effect is a large effect (typically $d>1$ ), so a power analysis shows that a sample size of eight participants achieves $80 \%$ power $(\alpha=.05)$ to observe the Pong effect. Given that there could be small effects of interest in the current experiment, we recruited more than this minimum number. A sample size of 30 gives us $80 \%$ power to detect an effect of $d=.53$.

Stimuli and apparatus The experiment was conducted on a 19-in. desktop display. The background was black. There was a 1.6- $\mathrm{cm}$ white circle, which served as the ball, and a $0.8-\mathrm{cm}$ wide white bar that extended the length of the screen, vertically. Within that bar were two small horizontal black bars that were separated by either 1.9 or $11.8 \mathrm{~cm}$. The area in between the two horizontal black lines served as the paddle with which the participants tried to block the ball (see Fig. 1). The paddle used to block the ball was either red or blue. This coloring allowed for distinctions to be made between trials in which the participants had control versus trials in which the paddle was automated. The color for each condition remained constant for the duration of the trials for each participant, but was randomly assigned between participants. Said another way, the first participant would always see a red paddle on those trials in which he or she had control over the paddle, and a blue paddle anytime the paddle was automated. The second participant would always see a blue paddle on those trials in which he or she had control over the paddle, and a red paddle any time the paddle was automated.

The paddle's vertical placement was controlled by a joystick that participants moved. The ball moved at one of six speeds ranging from 26 to $67 \mathrm{~cm} / \mathrm{s}$ from left to right (taking between 1,724 and $493 \mathrm{~ms}$, respectively, to reach the paddle) along a diagonal, changing directions randomly. The angle of the direction change remained constant within an individual trial, but varied by speed between trials (e.g., the angle was more obtuse for faster speeds and more acute for slower speeds).

Of the 288 trials, 24 involved the ball moving at the slowest speed and 24 at the fastest speed. Speeds 2 and 5 each had 48 trials each, and the two middle speeds had 72 trials each. This allowed us to have additional trials at the more ambiguous speeds. This did not change the range of experimental speeds, but simply made the theoretically most ambiguous (in relation to their classification of more like the slow or more like the fast anchors) speeds appear more frequently. This increased our ability to detect differences at these critical midrange points.

In order to guard against a subjective experience that the paddle could still be controlled even when it was automated, we added a survey at the end of the experiment in order to ascertain whether the subjects believed they could control it. The survey said:

After a few trials, did you feel that you had any control over the [automated paddle color] automated paddle? Enter the number that best corresponds to your experience: 


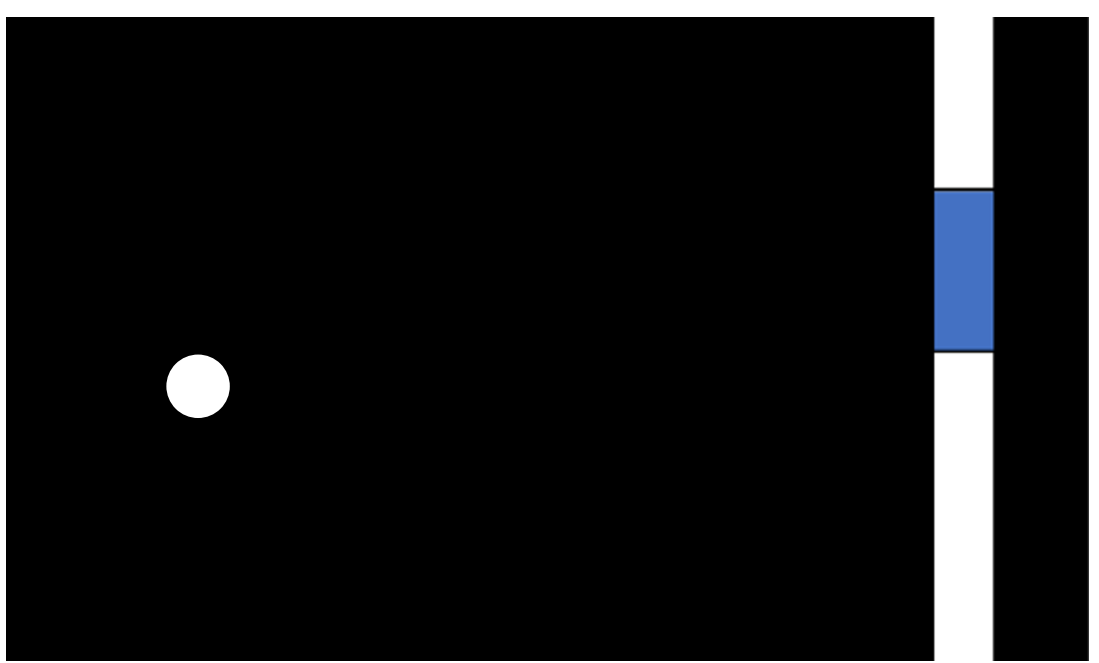

Fig. 1 A representation of the display used for the experiment. The white circle served as the ball, which bounced across the screen. The blue area between the two horizontal black lines represented the paddle with which

1. Yes, I felt I could control it throughout the experiment.

2. Sometimes I felt I could have some control over it.

3. No, I almost never felt that I could control it.

Procedure At the beginning of the experiment, participants were trained on the two anchor speeds, one slow $(18 \mathrm{~cm} / \mathrm{s})$ and one fast $(74 \mathrm{~cm} / \mathrm{s})$. The ball moved linearly across the screen at each of these anchor speeds three times (six in total), in a random order, without a paddle, and participants were told (via text on the screen) either "This is slow" or "This is fast." Following this initial exposure, participants were exposed to the anchor speeds again, but this time the participant was not told which speed would be shown and instead had to respond as to which speed was just demonstrated. Each anchor speed was shown three times (for a total of six additional trials), the order of which was randomized. They were then asked to indicate if the ball moved at the slow or fast speed, and participants entered their responses by pressing the corresponding buttons on the joystick. They were given feedback following each response via text on the screen. At the end of the training, they were given the opportunity to restart the training if they wanted to, which no one did. All participants correctly identified the slow and fast training speeds (in all the reported experiments), and thus no participants were excluded for this reason.

There were three kinds of test trials. The first trial type was the typical small paddle trial wherein the ball bounced across the screen and participants were tasked with trying to block the ball by moving a joystick to move the corresponding virtual paddle, which was small. The second trial type was the same as the first, except this time the paddle was 5 times longer. These two trial types will be referred to the small controlled paddle and the big controlled paddle, respectively. These two trial types represent the typical Pong task. the participant had to try and block the ball. The paddle length varied between trials. (Color figure online)

For the third trial type, the paddle was the same size as the small controlled paddle; however, this paddle was automated. When the paddle was automated, it was automated from the start of the trial and was automated throughout the entire trial. As a result, there was complete automation of Stage 3 and Stage 4 . The movement of the automated paddle was nonbiological. Instead of smooth, continuous movements, the automated paddle appeared in each location. The paddle appeared at one location, then disappeared and reappeared at a different location. The reappearance coincided with the exact vertical position of the ball at the moment of reappearance. The repositioning of the paddle occurred every $188 \mathrm{~ms}$. This was done so that the overall blocking performance of the automated paddle mimicked that of a participant controlling the big paddle. Thus, the automated paddle had the visual appearance of the small paddle, the blocking success of the big paddle, and was automated.

The color of the paddle designated whether the paddle was controlled or automated. For some participants, the blue paddles were controlled, and the red paddles were automated. For other participants, the red paddles were controlled, and the blue paddles were automated. Color assignment was randomized across participants.

After each attempt to block the ball, participants indicated whether the ball moved more like the fast anchor speed or more like the slow anchor speed. They made their response by pressing the left or right button on the joystick, respectively. The researcher watched the first several automated trials to ensure that the participant was not trying to control the paddle. If the participant was trying to control the automated paddle (by moving the joystick as if they were in control), the researcher would kindly remind them that when the paddle was the color designated automation, the participant did not have to control it (for a visual representation of example trials, see Fig. 2). 
Each block contained 36 trials. There were 12 trials for each paddle condition (small automated, small controlled, and big controlled paddle) composed of one repetition each of the slowest and fastest speeds, two repetitions each of the second slowest and fastest speeds, and three repetitions each of the two middle speeds for each of the three paddle sizes. Order within block was randomized. Participants completed eight blocks for a total of 288 test trials. After all 288 trials, the participants were given the survey and asked to respond accordingly.

\section{Results}

In order to avoid any confounds that a belief of control may have had, any participant who responded that they felt they could control the automated paddle throughout the experiment were excluded. This led to the exclusion of three participants. For the remaining 27 participants, their speed judgments were analyzed with separate binary logistic regressions in order to calculate the point of subjective equality (PSE) for each participant for each of the three paddle conditions. These PSEs for each participant, for each paddle, were then submitted to a boxplot analysis to look for outliers. An a priori criterion was set such that any participant with one score that was three times greater than the interquartile range (IQR) or two separate scores greater than 1.5 times the IQR was identified as an outlier. Given this cutoff, one additional participant was excluded. Finally, one participant had blocking performance that suggests they were not paying attention (only $25 \%$ blocked with the big paddle). For that reason, they were also excluded from further analyses, leaving 25 participants.

The automated paddle was programmed to successfully block the ball approximately $95 \%$ of the time. Results showed that ball-blocking performance with the automated paddle slightly exceeded that target $(M=$ $97 \%, S D=2 \%$ ). Ball-blocking performance was significantly better with the small automated paddle than with the big controlled paddle $(M=89 \%, S D=6 \%), t(24)=$ $6.95, p<.001,95 \%$ CI $[6 \%, 10 \%]$, and the small controlled paddle $(M=45 \%, S D=8 \%), t(24)=36.48, p<$ $.001,95 \%$ CI $[49 \%, 55 \%]$.

The purpose of this study was to determine whether perceived ball speed with the automated paddle would be like perceived ball speed with the small controlled paddle (same visual size) or with the big controlled paddle (similar ball-blocking performance). As shown in Fig. 2 , the automated paddle induced a PSE somewhere between the control paddles. A paired-samples $t$ test between the small controlled paddle PSEs and the small automated paddle PSEs showed a significant difference, $t(24)=3.001, p=.006,95 \%$ CI $[0.90,4.89]$. There was also a significant difference between the small automated paddle and the big controlled paddle, $t(24)=2.12, p=$ $.044,95 \%$ CI $[0.05,3.73]$.

It appears as if perceived ball speed was unaffected by the paddle when it was automated. Indeed, the difference between the PSE for the small automated paddle and the point of objective equality (POE; $45.98 \mathrm{~cm} / \mathrm{s}$; calculated as the average of the six test speeds) was not significant, $t(24)=0.27, p=.79,95 \%$ CI $[-1.64,2.15]$.

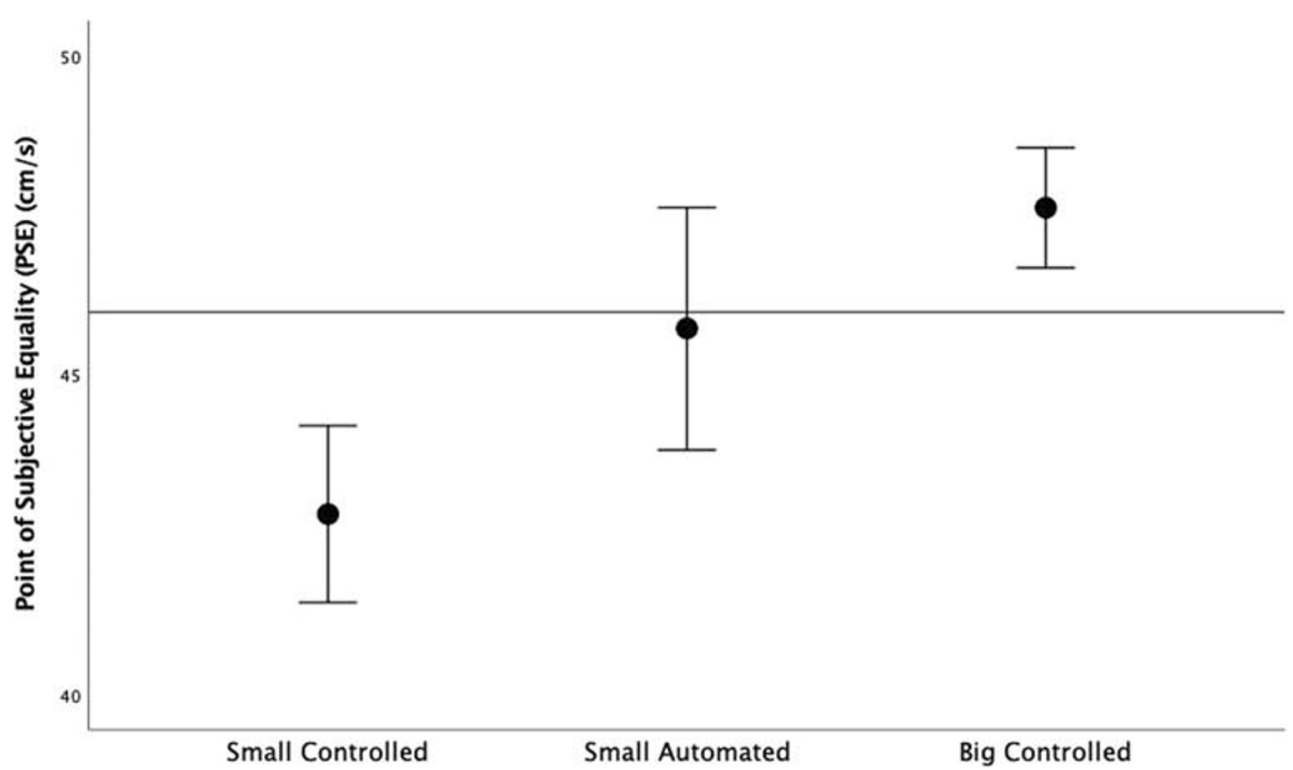

Fig. 2 PSEs for the three paddle conditions. Error bars represent the $95 \%$ confidence interval calculated within subjects. The horizontal line across the graph represents the point of objective equality (POE) 


\section{Discussion}

Results indicated that participant's perceived speed on trials in which the automated paddle was employed was neither in line with their capabilities nor with the overall performance of the automated paddle. If participants had the (perhaps implicit) intention of acting with the automated paddle, we would have expected their PSEs to be similar to their PSEs with the small controlled paddle. On the other hand, if participants' perceptions were influenced by the automated paddle's performance, we would have expected PSEs to be similar to PSEs with the big controlled paddle. However, neither appears to be the case. Instead, participants reported the speed when using the automated paddle as in between the perceived speeds when using the small controlled and big controlled paddles. This pattern of results could be caused by one of two explanations. The first possibility is that there was an averaging of perceptual information. Said another way, perhaps the participants' abilities to act with the small controlled paddle and the small automated paddle's performance were averaged when perceiving speed when using the small automated paddle. Another possible explanation is that participants were not influenced by the difficulty associated with the small paddle size, nor were they influenced by the performance of the automated paddle. This would result in participants' perceptual systems ignoring action or performance information altogether and instead relying purely on the optical information. This latter possibility is certainly more parsimonious than the former possibility.

With that said, and given concerns in the field surrounding replicability (Open Science Collaboration, 2015), we wanted to do a direct replication.

\section{Experiment 2}

In order to verify the pattern of results in Experiment 1, we ran a direct replication.

\section{Method}

We recruited 27 undergraduates from the available research pool at Colorado State University. The stimuli, apparatus, and procedure were the same as in Experiment 1.

\section{Results}

The data were analyzed as in Experiment 1. One participant, who indicated the belief that they could control the automated paddle throughout the experiment, was excluded. No participants were identified as outliers.

There was a significant difference between PSEs for the small controlled paddle and the small automated paddle, $t(25)=3.25, p=.003,95 \%$ CI $[0.97,4.32]$, replicating the finding in Experiment 1. The difference between the small automated paddle and the big controlled paddle was not significant, $t(25)=1.495, p=.147,95 \%$ CI $[-0.40,2.53]$ (see Fig. 3). However, the trend was in the same direction. When combined across Experiments 1 and 2, the data yielded a significant difference between the small automated paddle and the big controlled paddle, $t(50)=2.60, p=.012,95 \%$ CI $[0.33,2.61]$. Given the small effect size, the larger sample size provided from combining the two studies was necessary to achieve statistical significance.

The small automated PSE was not significantly different from the POE, $t(25)=0.07, p=.95,95 \%$ CI $[-1.56,1.46]$.

\section{Discussion}

Results from this second experiment replicated the findings of the first experiment. However, these results still do not answer whether the PSEs with the small automated paddle represent an averaging, or a complete neglection of action and performance information, as detailed above. This is a critical distinction to make. If these data are caused by an averaging, then that means that the automated system is in fact influencing the participant's potential for action in a way that affects spatial perception, at least to some degree. If, on the other hand, these data are independent of both the participant's ability to act and the ball-blocking performance of the small automated paddle, then we have evidence that the automated system is not affecting the individual's potential for action. This would additionally suggest that not only is information about this form of automation not influencing perception, it additionally prevents information about an individual's own inherent ability to act from influencing perception.

To test these competing explanations, we need to change the ball-blocking performance of the small automated paddle. If we make ball-blocking performance of the small automated paddle roughly equivalent to the small controlled paddle, an averaging of the performance information as well as the user's ability would result in PSEs similar to PSEs when using the small controlled paddle. If, however, the same pattern of results emerges even when the "deck is stacked," so to speak, in one direction, this would suggest that information about the automated system is not influencing one's percept and is causing participants to neglect all action information and rely on purely optical information. Thus, we ran Experiment 3.

\section{Experiment 3}

The automated paddle was programmed to have ball-blocking performance similar to that of the controlled small paddle. 


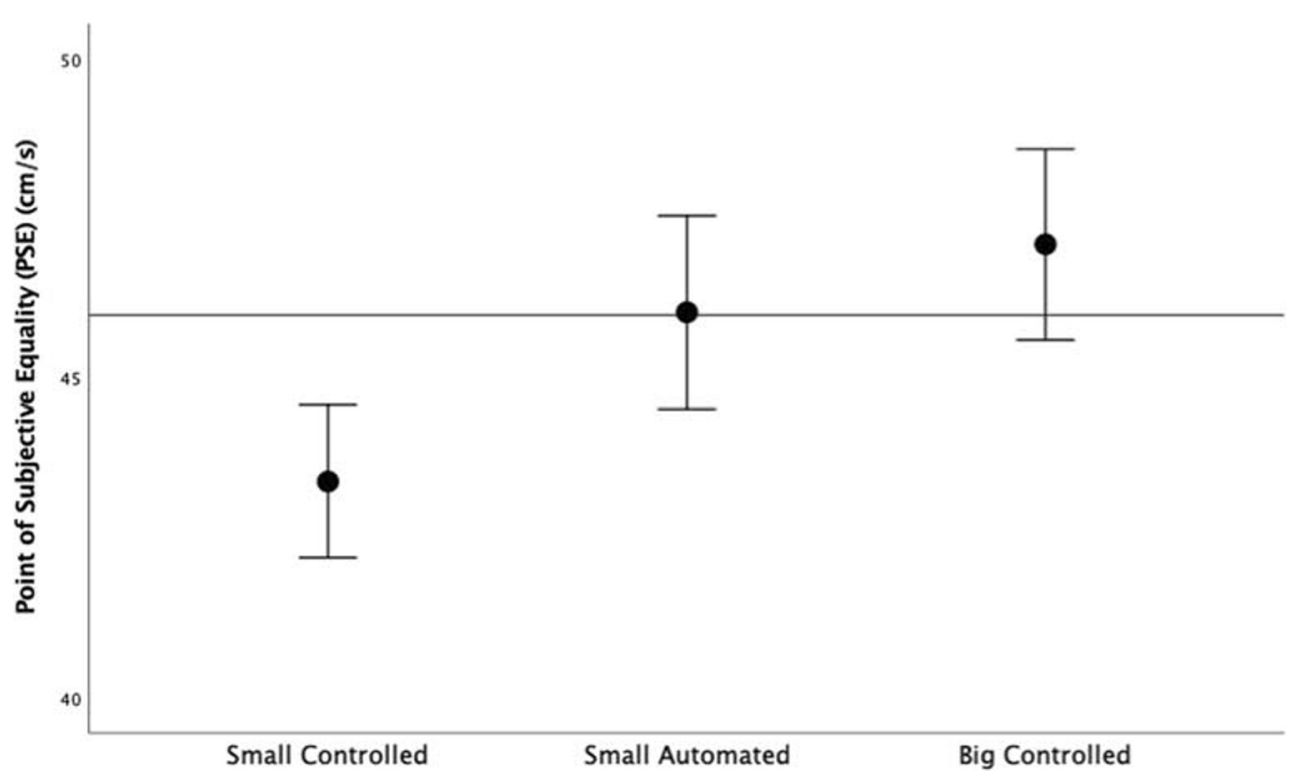

Fig. 3 PSEs for the different paddle conditions. Error bars represent $95 \%$ confidence intervals calculated within subjects. The horizontal line across the graph represents the point of objective equality (POE)

\section{Method}

Participants We recruited 30 undergraduates from the available research pool at Colorado State University.

Stimuli and apparatus The stimuli and apparatus were the same as in Experiment 2.

Procedure The procedure was the exact same as in Experiment 2 , with the following exceptions. In this experiment, the ballblocking performance with the small automated paddle was set to be approximately $45 \%$, to mimic the performance with the small paddle. To achieve this, the automated paddle was programmed to update its position every $188 \mathrm{~ms}$ with a random amount of $y$-axis positioning noise. The noise was randomly generated such that the paddle offset was anywhere between one and 50 pixels above or below the $y$-axis position of the ball. For reference, 50 pixels was the height of the small paddle. This position update rate and noise in the positioning of the paddle led to the paddle not always being in the necessary position to block the ball when the ball would reach the position of the paddle along the $x$-axis, thus leading to a blocking rate of $45 \%$.

\section{Results}

As a manipulation check, we examined ball-blocking performance for the three conditions. Ball-blocking performance with the small automated paddle $(M=44 \%, S D$ $=5 \%$ ) was not significantly different from that of the small controlled paddle $(M=43 \%, S D=9 \%), t(27)=$ $1.05, p=.305,95 \%$ CI $[-2.0,6.2]$. Performance with the small automated paddle was significantly worse than performance with the big controlled paddle $(M=89 \%, S D$ $=5 \%), t(27)=30.07, p<.001,95 \%$ CI [42.2, 48.3]. The small controlled paddle performance was also significantly worse than the big controlled paddle, $t(27)=35.23, p<$ $.001,95 \%$ CI $[44.6,50.1]$.

The data were analyzed as before. Two participants were excluded for indicating they thought they had control of the automated paddle, and no participants were identified as outliers.

Pairwise comparisons indicated a significant difference between the small controlled paddle and the small automated paddle $t(27)=2.79, p=.010,95 \%$ CI $[0.46,3.04]$, and a significant difference between the small automated paddle and the big controlled paddle, $t(27)=2.86, p=.008,95 \%$ CI [0.65, 3.95] (see Fig. 4).

There was no significant difference between the PSE for the small automated paddle in Experiment 3 and the POE, $t(27)=1.18, p=.25,95 \% \mathrm{CI}[-0.64,2.39]$. In addition, there was no significant difference between the PSE for the small automated paddle in Experiment 3 versus the PSEs for the small automated paddle collapsed across Experiments 1 and $2, t(77)=0.82, p=.42,95 \%$ CI $[-1.12,2.68]$.

\section{Discussion}

The PSEs in the automated condition of Experiment 3 were not statistically different than the results from Experiments 1 and 2. This suggests that the results in the first two studies were caused by a discarding of paddle information when the paddle was automated. If an averaging of a user's ability and the performance were causing 


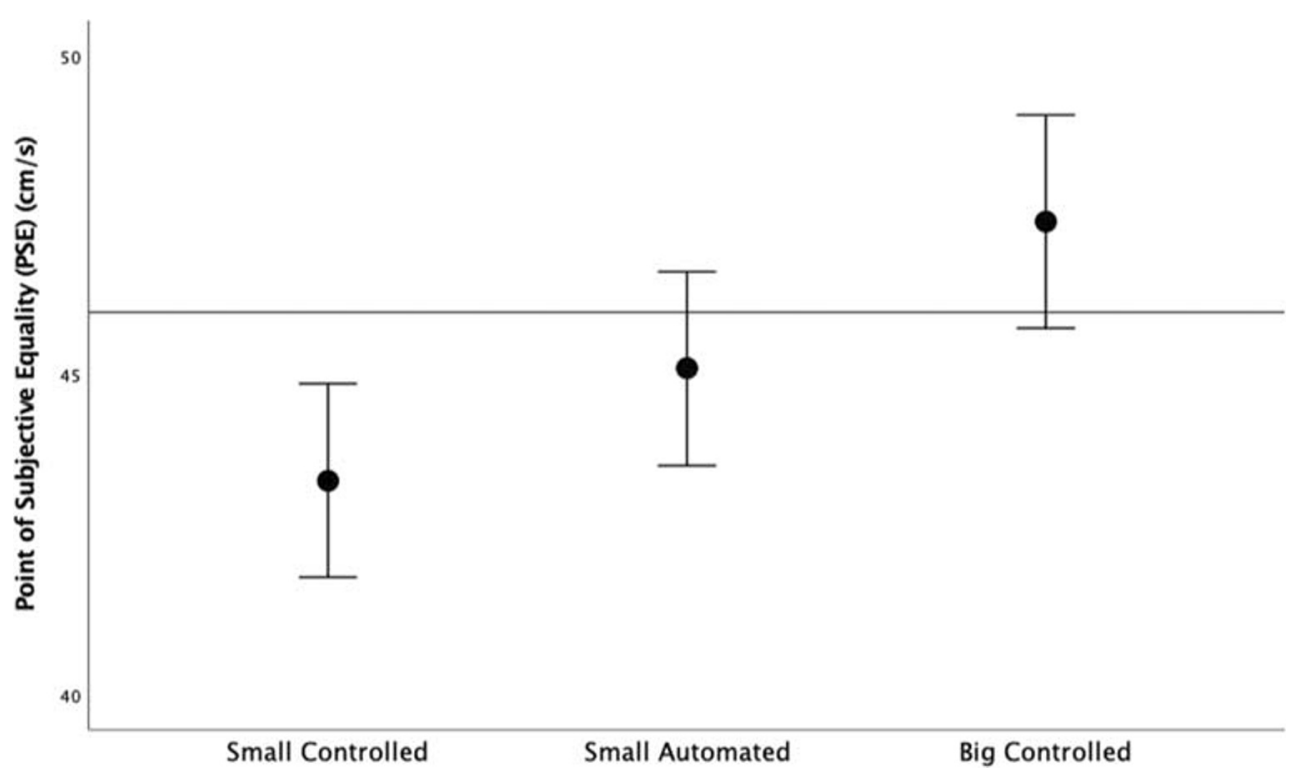

Fig. 4 PSEs for the different paddle conditions. Error bars represent 95\% confidence intervals, calculated within subjects. The dashed line across the graph represents the point of objective equality (POE)

the results in Experiments 1 and 2, in this current experiment we would have expected to see the PSEs when using the small automated paddle to be in line with the PSEs when using the small controlled paddle. However, because that was not the case, the results of the first three experiments are likely caused by a disregard for any action information. Instead, the perceptual system appears to be relying on only the visual information when using the small automated paddle. This is consistent with the results showing that the PSEs were similar to the POEs regardless of how well the automated paddle blocked the ball.

The current results suggest that automated paddles do not affect one's potential for action. Of course, this does not mean that automation can never influence perception. It is worth exploring whether we can ever evoke influence of an automated system's performance on perception. One way in which this could be done is to make the automation a tool which the participant has to engage, or intents to act with. If the environment is set up such that participants have to act until a certain parameter is met (at which point the automation takes over), it would make sense that there could be an influence of the automated system's performance on perception. This setup would allow the automation to exist in a way that allowed the participant's own action to result in the same outcome for all paddle sizes. By doing this, we could essentially make every trial equally easy, regardless of actual paddle size. It would stand to reason that if the user's ability to act with different paddle sizes is causing the distortions in perceived speed, then by using an automated aid that nullifies any difference in ease, we should nullify any differences in perceived speed if this form of automation influences perception. Thus, we ran Experiment $4{ }^{1}$

\section{Experiment 4}

\section{Method}

Participants We recruited 27 undergraduates from the available research pool at Colorado State University.

Stimulus and apparatus The stimuli and apparatus were the same as in Experiment 1, with the following exceptions. The paddle (represented by the area between the two black lines) was white in this experiment (see Fig. 5). Because automation was blocked, rather than intermixed, we did not use paddle color to indicate the presence of automation. There were three paddle sizes: $1.9,5.8$, or $11.8-\mathrm{cm}$ tall. The six ball speeds were equally distributed, rather than having more instances of the middle speeds, as was the case in the earlier experiments. Participants did not complete the postexperimental questionnaire regarding control.

\footnotetext{
${ }^{1}$ In the interest of full disclosure, Experiment 4 was conducted before Experiments 1-3. Because of this, there are discrepancies between the methodologies. It was not until after we ran Experiment 4 that we realized the benefit of including the survey. Additionally, we realized that by changing the distribution of trials across speeds, as we did in Experiments 1-3, we would be afforded greater sensitivity to calculate PSEs given the greater number of trials at the most ambiguous speeds.
} 


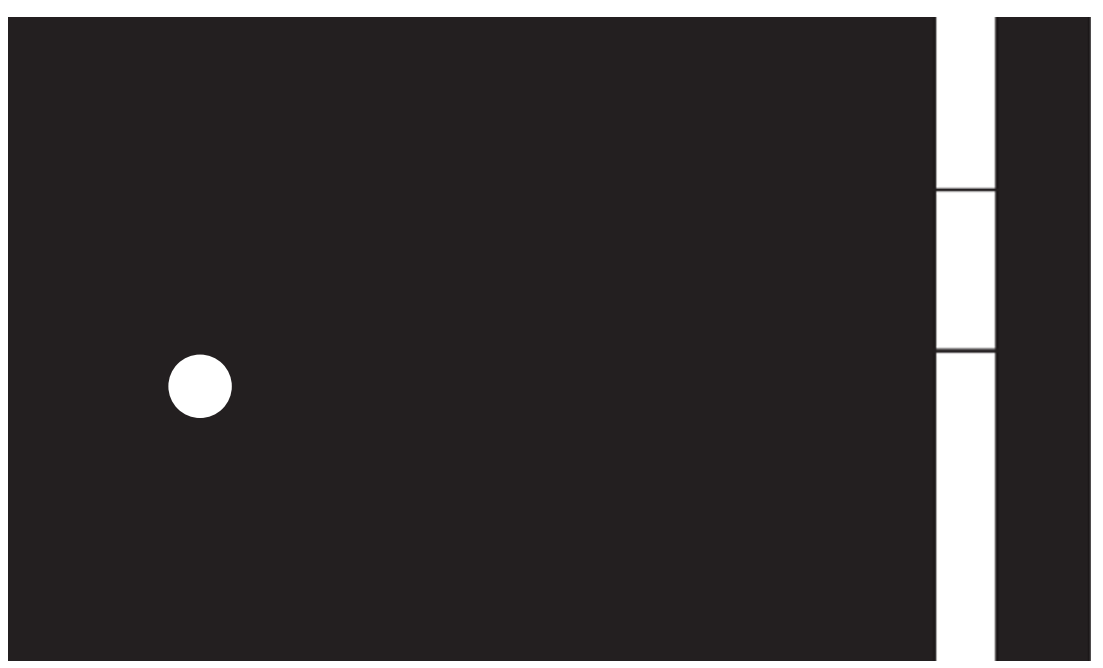

Fig. 5 A representation of the display used for the experiment. The white circle served as the ball, which bounced across the screen. The white area between the two horizontal black lines represented the paddle with which the participant had to try and block the ball. The paddle length varied between trials
Procedure Participants were initially trained on the anchor speeds, as in Experiments 1-3. They then completed two blocks of test trials. For the block corresponding to the noautomation condition, participants had full control of the paddle during every trial. For the block corresponding to the automation condition, participants started each trial by controlling the paddle. However, the computer took over control of the paddle when a certain condition was met. The condition was that participants had to align the center of the paddle within $1.9 \mathrm{~cm}$ of the vertical placement of the ball. This alignment had to occur within a certain window, which was when the ball had already traveled approximately one fourth of the screen's width (which took between 180 and $625 \mathrm{~ms}$, depending on ball speed). Once the automation took over, the paddle moved up and down in perfect synchrony with the ball's position (and was no longer affected by movement of the joystick). Because the condition was specified with respect to the midpoint of the paddle, engaging the automation was equivalent across the different paddle sizes. The automated paddle successfully blocked the ball every time the automation was employed.

At the end of each trial, participants indicated whether the ball moved more like the slow speed or more like the fast speed, regardless of whether automation was employed. Participants completed 144 trials in one condition, then 144 trials in the other condition. Order of conditions was randomized across participants. The first condition was labeled as the start condition. There was no postexperiment survey.

\section{Results}

The data were analyzed as before, and no participants were identified as outliers. We ran a repeated-measures analysis of variance (ANOVA), with paddle length and automation condition as within-subjects factors and starting condition as a between-subjects factor. There was a significant overall main effect for paddle length on PSE estimations such that the bigger the paddle, the slower the ball appeared to move, $F(2,50)$ $=21.38, p<.001, \eta_{\mathrm{p}}{ }^{2}=.46$. The interaction between paddle length and automation was trending towards significance, $F(2$, $50)=2.43, p=.099, \eta_{\mathrm{p}}{ }^{2}=.09$. This trend led us to question whether there were additional outliers with respect to differences between conditions. We explored the Pong effect data (PSEs with the big paddle - PSEs with the small paddle) for each condition and found two participants with Pong effect scores 1.5 times greater than the IQR (see Fig. 6). When these participants were excluded, the interaction between paddle length and automation was significant, $F(2,46)=4.40, p=$ $.018, \eta_{\mathrm{p}}{ }^{2}=.16$ (see Fig. 7). The remaining analyses were similar regardless of these participants inclusion, so results are reported having kept their data in the analysis.

There was no significant interaction between paddle size and the start condition, $F(2,50)=0.13, p=.88, \eta_{\mathrm{p}}{ }^{2}=.01$. There was no significant main effect for the automation $F(1$, $25)=.74, p=.40, \eta_{\mathrm{p}}{ }^{2}=.03$, nor was there an interaction between automation and start condition, $F(1,25)=.02, p=$ $.88, \eta_{\mathrm{p}}{ }^{2}=.00$. When we considered order effects (based on the considerable effects reported in Witt, Sugovic, \& Taylor, 2012), there was a nonsignificant (Paddle Length $\times$ Automation $\times$ Order) interaction $F(2,50)=0.93, p=.40$, $\eta_{\mathrm{p}}{ }^{2}=.04$, suggesting that order of experience was irrelevant for these findings.

To further explore the data, we analyzed the Pong effect in the automation conditions for each of the start conditions separately. The Pong effect was significant when using automation for the no-automation start condition, $F(2,26)=4.19, p=$ 


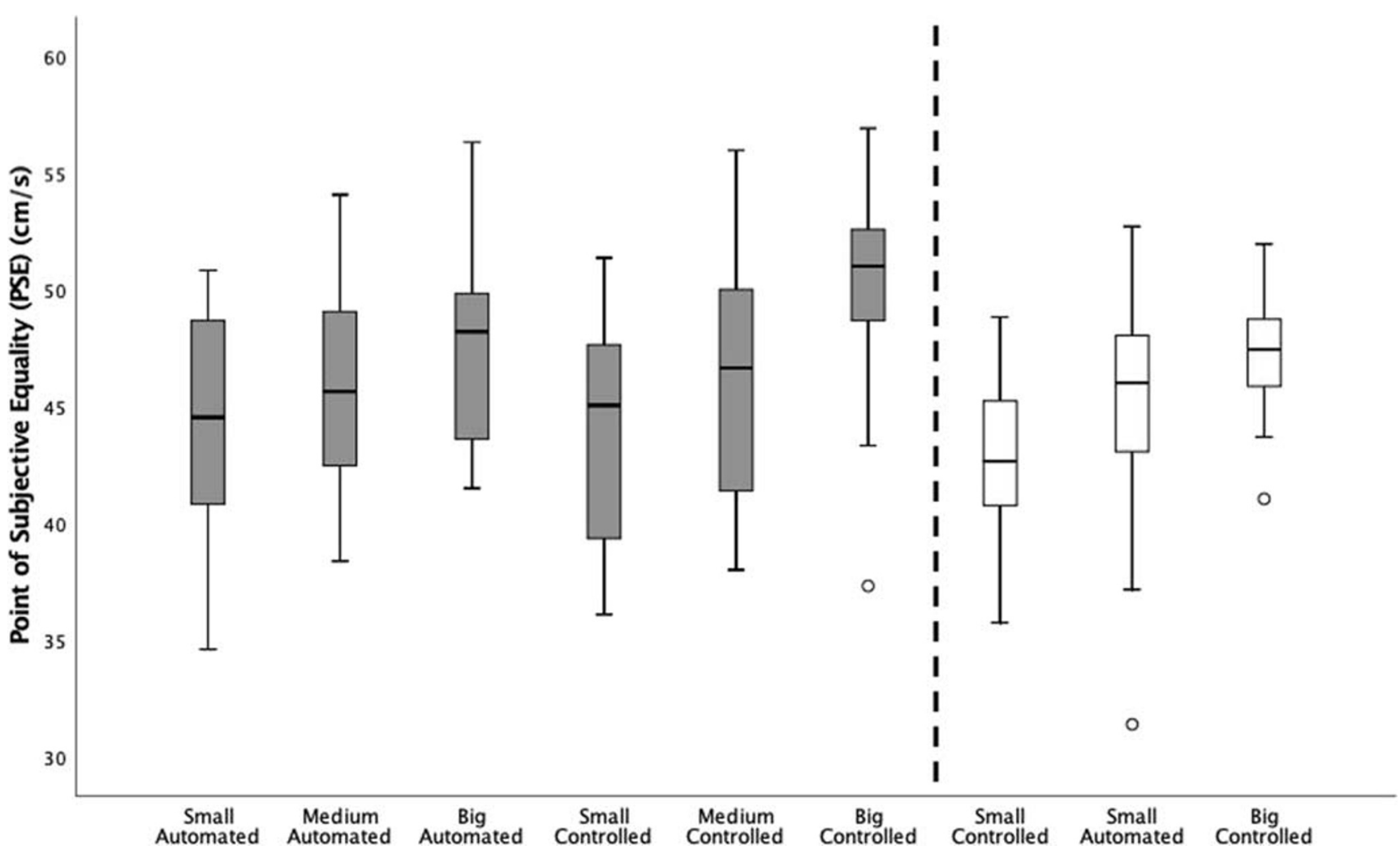

Fig. 6 Boxplot analysis of the PSEs for each paddle for the Experiment 4 (boxes in gray on the left) compared with boxes for Experiment 1 (white controlled paddle of Experiment 4 led us to replot the data by participant Pong effect (big paddle PSE - small paddle PSE). Note the variability boxes on the right). While there were no outliers that met our a priori criteria for the present experiment, the substantial variability in the big differences of the small controlled and the big controlled PSEs between Experiment 4 and Experiment 1
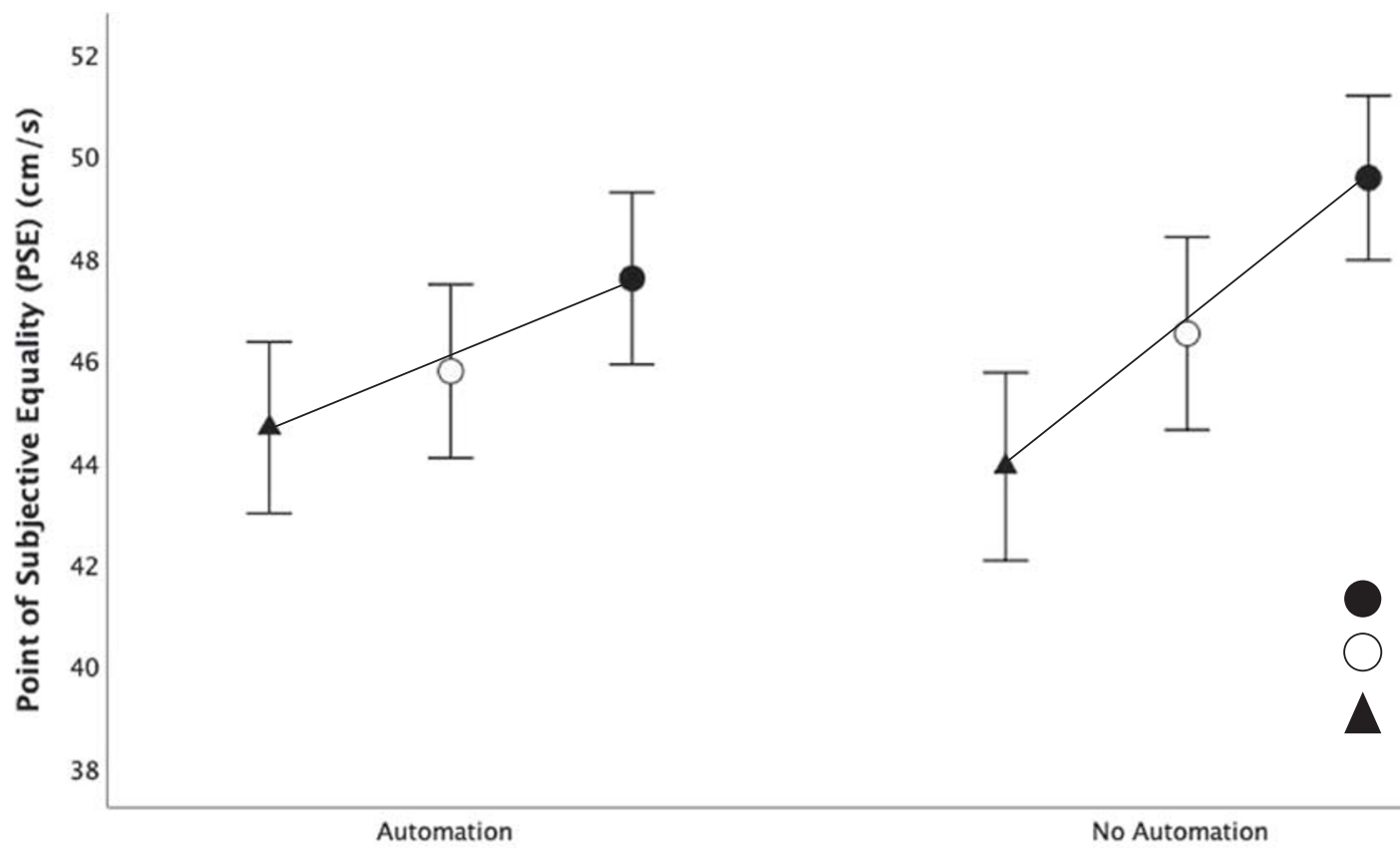

$=$ Big Paddle

= Medium Paddle

$\mathbf{\Delta}=$ Small Paddle

Automation

No Automation

Trial Condition

Fig. 7 Mean PSEs plotted for each paddle size by trial conditions, collapsed across start condition. Error bars are 95\% confidence intervals, calculated within subjects 
$.027, \eta_{\mathrm{p}}{ }^{2}=.26$, and significant when using automation for the automation start condition, $F(2,26)=5.59, p=.010, \eta_{\mathrm{p}}{ }^{2}=$ .30 .

Participants' blocking performance proportions in the noautomation condition is as follows: small $(M=.42, S D=.49)$, medium $(M=.66, S D=.47)$, and large $(M=.90, S D=.29)$. In the automation condition, participants were able to engage the automation (and thus block the ball) a mean proportion of .95 $(S D=.22), .95(S D=.21)$, and $.94(S D=.24)$ for the small, medium, and large paddle trials, respectively (see Fig. 8).

\section{Discussion}

The outcomes from Experiment 4 disrupt the idea that the visual system processes only visual information in the presence of automation. In Experiments 1-3, perception of ball speed aligned with actual target speed when the paddle was automated. In contrast, in Experiment 4, perceived ball speed varied across the three sized automated paddles. The outcomes of Experiment 4 also disrupt the idea that when there are no differences in ball-blocking success, there should be no differences in perceived ball speed. In the General Discussion, we attempt to find a simple explanation that can account for the differs patterns observed across the four experiments.

One alternative explanation for the results could be that the paddle movement differences inherent between the automation and no-automation conditions was sufficient to elicit the effects found here and in the first three experiments. However, as mentioned above, Witt et al. (2012) found that even when watching nonbiological movement of a computer that performed the blocking task perfectly, participants still experienced perceptual distortions if they had acted themselves. Therefore, it seems unlikely that the movements alone would produce the observed results.

Again, because the Pong effect remained in the automation conditions, these data seem to fly in the face of the actionspecific account of perception. Remember, the claim from action-specific researchers has been that wherein a change in performance is observed, there should also be a change in perception (e.g., Witt, 2011a, b). Again, the conditions that engaged the automation were the exact same between paddle lengths, such that it was equally easy to engage with each paddle. Therefore, according to the action-specific account of perception, there should have been no difference in perception. Additionally, this result seems to suggest that the Pong effect cannot be explained by the visual input account put forth by Kirsch and Kunde (2018). The results seem to suggest a response bias account on behalf of the paddle sizes could explain the Pong effect.

With that said, and of particular note, is the fact that participants being required to act immediately preceding the automation taking over may have contributed to these results. According to the motor simulation account of action, when observers intend to perform an action, they implicitly conduct a motor simulation of that action (Jeannerod, 1994, 2001). The outcomes of this simulation include the anticipated outcomes of the action, such as the probability of success. These outcomes subsequently can influence spatial perception (Witt \& Proffitt, 2008; Witt, South, \& Sugovic, 2014). In the present experiment, the actions involved in engaging the automation

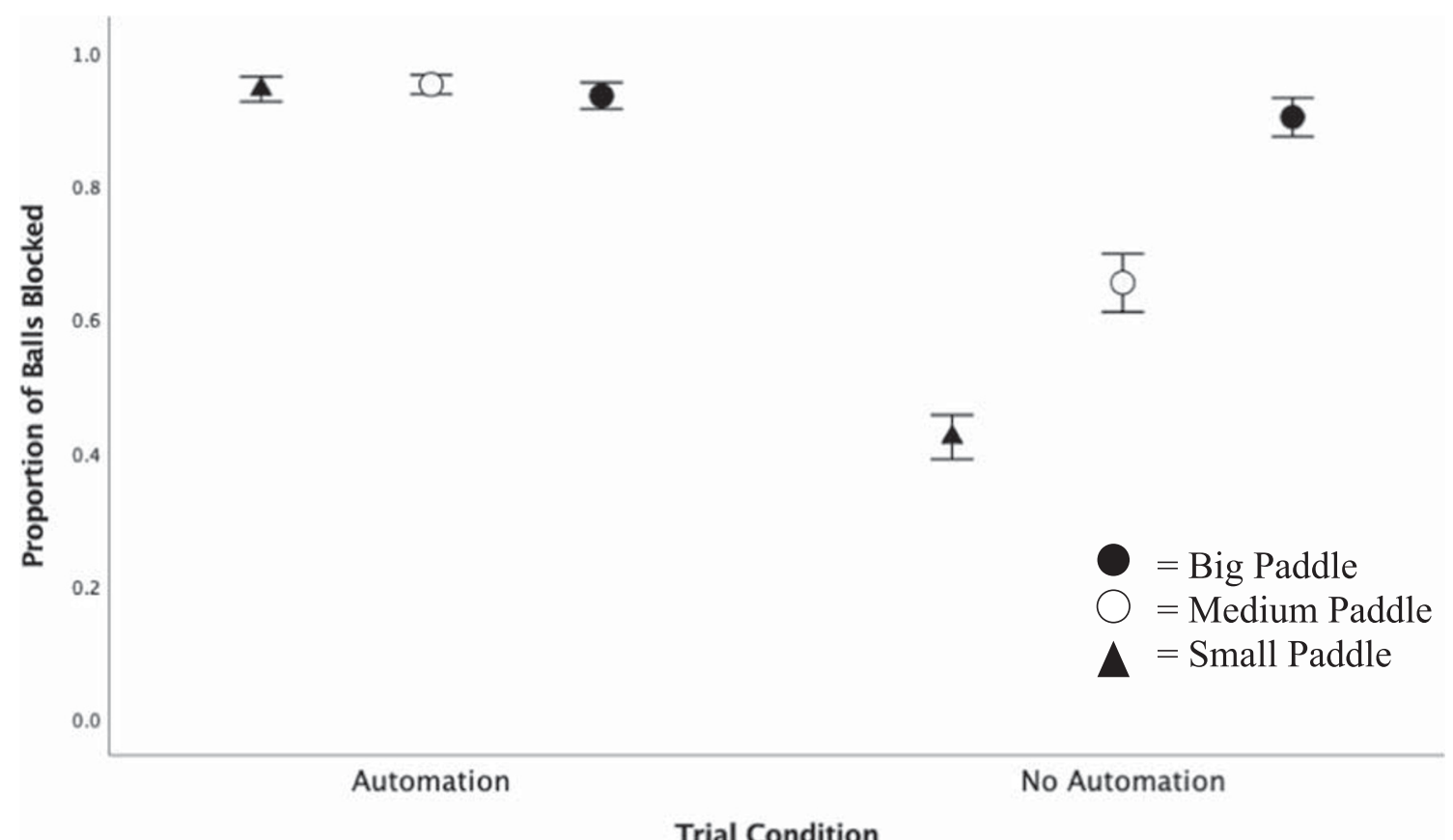

Trial Condition

Fig. 8 Proportion of balls blocked by paddle length, automation condition, and starting condition. Error bars are 95\% confidence intervals, calculated within subjects 
are identical to the actions involved in blocking the ball. The only difference is the duration that the action needs to be performed. When the observer has to initiate an action to engage the automation, these actions could give rise to similar processes as those involved when trying to block the ball without automation. This engagement of the automation is the key difference between Experiments 1-3 and Experiment 4. The engagement of automation could have invoked the same processes that lead to action-specific effects in the first place.

\section{General discussion}

Automation serves many functions in everyday life. In some cases, automated systems replace the human, while in others the automation functions to enhance human ability (de Visser, Pak, \& Shaw, 2018; Hancock, Nourbakhsh, \& Stewart, 2019; Janssen, Donker, Brumby, \& Kun, 2019; Taylor, ReinermanJones, Szalma, Mouloua, \& Hancock, 2013; Wickens, 2018). For automation to incorporate seamlessly into daily life, it is important to know whether the perceptual experience of the environment is different when using automation than it is with other kinds of action-based enhancements. Perhaps if automation influences perception, it will also be incorporated seamlessly into daily life, much like how our own abilities to act are incorporated seamlessly into daily life. In contrast, if automation does not influence perception, this could lead to errors when using automation, such as neglecting to intervene while supervising an automated process that has failed. This sort of human-automation interaction could have grave consequences in self-driving vehicles, for example. A user who fails to consider their ability to brake, and thus regains control from the automation later than necessary, could end up crashing the vehicle. The supervisory control inherent in humanautomation interaction has consequences beyond driving and into robotics (Chen \& Barnes, 2014), drone operation (Hansen, Alapetite, MacKenzie, \& Møllenbach, 2014; Taylor, Alicia, Turpin, \& Surana, 2017), and even health care (Kaber, 2018).

Our main research question was whether augmented abilities due to automation would influence spatial perception. Prior research has shown that perceivers can augment their abilities to act through tool use. Reach-extending sticks make objects just beyond arm's reach appear closer (Linkenauger, Bülthoff, \& Mohler, 2015; Morgado, Gentaz, Guinet, Osiurak, \& Palluel-Germain, 2013; Osiurak, Morgado, \& Palluel-Germain, 2012; Witt, 2011b; Witt \& Proffitt, 2008; Witt et al., 2005). Increasing the size of a paddle used to block a moving ball reduced perceived ball speed (King et al., 2017; Witt et al., 2014; Witt \& Sugovic, 2010; Witt et al., 2012; Witt et al., 2016). And even using a car can make distances look closer, compared with walking (Moeller et al., 2016).

\section{Spatial perceptual processes ignore automation}

Our research question was whether perceptual processes would be sensitive to performance enhancements with automation, just like they are with tools. With respect to the current version of automation, the outcomes from all four experiments provide a decisive answer to this question. Perception was wholly independent of the automation used here. When an automated paddle was intermixed with controlled paddles, perception ignored the automated paddle's rate of success and perceived ball speed with respect to visual information only (Experiments 1-3). When automated paddle trials were blocked and paddle size changed, but ball-blocking performance was high, regardless of size, perception ignored this aspect of the automated paddle's performance as well (Experiment 4). In the case of these automated paddles, perceptual processes ignored the automation's outcomes.

Automation not influencing perception in the current experiments does not guarantee automation would never influence spatial perception. In the present experiments, we employed automation of the decision stage (Stage 3) and action stage (Stage 4) in Experiments 1-3, and just the action stage (Stage 4) in Experiment 4 (Parasuraman et al., 2000; Wickens, 2018). Results from each of the studies indicated that the performance of the automated system does not influence participants' perception.

That outcomes generated by automation are ignored by the perceptual system while at the same time outcomes due to augmented abilities via tool use are influential for perception raise a distinction between tools and automation. While both can augment abilities, the perceptual system seems to treat them differently. If these perceptual differences translate to subsequent behavioral consequences, this suggests that conclusions drawn about how the mind treats tools (for example, training regimes or the nature of the kinds of errors that are made) will not translate to how the mind treats automation.

\section{Underlying mechanism: Motor processes that anticipate the outcomes}

This discrepancy between how the visual system treats automated enhancements versus tool-based enhancements suggests that what matters for the perceptual system is not simply performance information. While the data lead to the claim that the perceptual system ignores the outcomes from automated paddles, the results from Experiment 4 highlight an unresolved issue for the action-specific account of perception. This limitation of the account revolves around the lack of specified mechanism by which action exerts its influence on perception (Firestone, 2013; Witt, 2015). There are two components to this mechanism. One is the information about action that influences perception and the second is the means by which this information exerts its influence. 
Regarding the first component, prior research suggests that one source of information about action comes from motor processes that anticipate the outcomes of the action (Jeannerod, 2001; Witt \& Proffitt, 2008). For example, in the Pong task, the perceiver can anticipate that they will be more successful blocking the ball with the big paddle than with the small paddle, and these anticipations (rather than the actual outcomes) influence perception. Because anticipations are internal states, we cannot measure them directly. Instead, we infer their presence.

There are three nonmutually exclusive types of anticipation that could influence perceptual processes. One type is a nonmotor anticipation that predicts what will happen without relying on any motor processes. This anticipation could predict whether the ball would be blocked or not, which could then influence subsequent perception of ball speed. Had this type of anticipation exerted an influence on perception of ball speed, we would have expected to see differences in judged ball speed between Experiments 1 and 2 when compared with Experiment 3, given the differences in the proportion of balls successfully blocked by the automated paddle. In contrast, perceived ball speed was the same in the automated paddle condition across the three experiments and did not differ from actual ball speed. This suggests a sole reliance on visual information rather than anticipating the outcomes of the trial. The involvement of this kind of anticipation would also have predicted no differences in perceived ball speed across the various automated paddle conditions in Experiment 4, which similarly does not align with the obtained results. These data patterns suggest that such nonmotor anticipation processes are not involved in action-specific effects on spatial perception.

Another type of anticipation is augmented motor anticipation for which motor processes anticipate the perceiver's success given the augmentation to their abilities. This type of anticipation is argued to be why tool use affects spatial perception (see above). For whatever reason, it appears that augmenting one's ability to block the ball by automating the paddle did not engage these processes in a way that subsequently influenced speed perception. Had this augmented motor anticipation been able to explain the results, the performance of the automated paddle would have needed to result in changes to the participants' perceptions. However, despite performance changes with the automated paddle, which mirror the differences between the small and big paddle normally, there was no change in estimated ball speed between Experiments 1-2 and Experiment 3. Thus, there is a distinction between augmentation via tool use and augmentation via automation.

The third type is hypothetical motor anticipation for which the actor anticipates the outcomes as if they were performing the task on their own. We have previously proposed that this kind of anticipation affects perception of ball speed when watching someone else do the Pong task (Witt et al., 2014). In that earlier research, even though participants were watching someone else do the task, they perceived the speed of the ball as if they themselves were playing with the current paddle.

We have also proposed that this kind of anticipation is involved when observing a computer play (Witt et al., 2012). In this case, the participant needed to have had some experience playing the Pong task for the Pong effect to emerge. But once they had their own experience playing, they perceived the ball as moving faster when the computer played with a small paddle than when the computer played with a big paddle. The patterns in perceived speed were as if the participant were playing with each paddle. This outcome suggests that participants may need to first engage in some action to initiate hypothetical motor anticipatory processes when observing a nonbiological entity. After having had their own experience playing Pong, participants perceived the speed of the ball as if they were controlling the paddle, so the Pong effect emerged even though there were no differences in ballblocking performance across the three paddle sizes when the paddles were controlled by the computer.

The involvement of these hypothetical motor anticipation processes in action-specific effects could explain the results obtained here. When participants had to act to engage the automation (as in Experiment 4), they seemed to perceive ball speed as if they were continuing to control the paddle. When participants did not have to act to engage the automation (as in Experiments 1-3), perceived ball speed was unaffected by their own anticipated performance. This account is speculative, and it highlights gaps in our current understanding. In this account, what needs to be explained are the conditions under which these hypothetical motor anticipation processes are engaged. One option is that the initial requirement to act to engage the automation also engages the hypothetical motor anticipation processes. Our data do not directly speak to this issue because there were other differences between the first three experiments and Experiment 4 that we did not systematically explore, such as whether the trials are intermixed or blocked. Future research will be necessary to fully determine the specific processes involved and the boundary conditions under which they are involved.

In summary, while the data are consistent with a role for hypothetical motor anticipation processes influencing spatial perception, future experiments designed to specifically address this topic are necessary. Understanding the mechanism will also provide concrete evidence that the observed effects are perceptual, a question that is ripe for debate.

\section{Limitations and future directions}

There are several limitations of the current experiments. First, we limited our automation to a single level. While it is easy to conceptualize automation as a single thing, the reality is that the level of automation, and the stage that is automated, form a 
complex interaction of various "degrees of automation" (Onnasch et al., 2014). It is entirely possible that the results would be different for different levels of automation at different stages of processing. Secondly, we have automated a performance-based effect. The field of action-specific perception also details effects based on energetics (Stefanucci et al., 2005; Tenhundfeld \& Witt, 2017; Witt et al., 2011). As was found in Moeller et al. (2016), the inclusion of automation in the form of a vehicle seemed to affect perception when dealing with energetics. Perhaps the reason this effect was found pertained to the relatively low level of automation in their experiment, contrasted with the high level in ours (Onnasch et al., 2014; Parasuraman et al., 2000; Sebok \& Wickens, 2017). Further research is needed to understand the differences between automation in these two domains.

One area for future research to examine is the role of automation's behavior in leading to its inclusion in an individual's percept. Automation behavior refers to the degree with which the automation acts like a human. There has been considerable exploration into the effects of the type of automation, albeit not in reference to embodiment. For example, research has shown that humans are more likely to trust automation that makes errors similar to those of a human (Madhavan \& Wiegmann, 2007), and prefer autopilot systems that control an airplane like the pilot does (Wiener \& Curry, 1980). Perhaps automation that behaves differently will have different effects on perception. This is supported by earlier research, which shows that the way in which a computer performs a task influences the observer's perceptions (Witt et al., 2012).

Additionally, future research should seek to examine the degree to which the results were a function of action automation, per se, or some other factor. Because of the nature of automation, it is inherently difficult to disentangle questions of agency, haptic feedback, and motor control, from the automation itself. Therefore, questions remain as to the specific mechanism which led to the observed results. Said another way, perhaps it is the discrepancies in haptic feedback that elicited the null results of Experiments 1-3, but not in Experiment 4. However, future research would be needed to fully understand the mechanism that contributed to the results here. Understanding of that mechanism could help develop our understanding about the underlying mechanism of action-specific perception.

\section{Conclusion}

In closing, we have run four experiments to evaluate whether an automated system's performance influences individual's percept. Results indicate that the performance of the automated system used here does not influence perception. When an action decision was automated, participants perceived ball speed independently from the paddle's performance. When the action decision was not automated, but the action itself was automated, participants also perceived ball speed independently from the paddle's performance. In this latter case, perception was influenced by the participants' own anticipated performance as if they had been controlling the paddle.

These data suggest that, at least in the current form, when human abilities are augmented by automation, the perceptual system discards performance information. From this we can infer that the perceptual system is not treating automation as a tool in the way it would, for example, a stick. Whereas questions remain regarding the mechanism that underlies actionspecific perception, our data are consistent with the involvement of a hypothetical motor anticipation process. This process anticipates motor outcomes in a hypothetical situation, such as if the perceiver had control over something that was being controlled by another person or an automated process.

From an applied perspective, these data raise concerns over the implications of action automation in the real world. If automation results in a perceptual discarding of information about both the user's ability to act and the automation's ability to act, the transfer of control from an automated system to a human may result disastrous consequences for both performance and safety.

Author note Nathan L. Tenhundfeld, Department of Psychology, University of Alabama in Huntsville, Huntsville, AL 35899, USA. Jessica K. Witt, Department of Psychology, Colorado State University, Fort Collins, CO 80523, USA. This work was supported by a grant from the National Science Foundation to J.K.W. (BCS-1348916 and BCS-1632222). During peer-review, data can be accessed at https:/osf.io/ jya3x/?view_only=f9293ae806e74dc6a18a7b7d8b6d8be4. The authors would like to thank Nick Fitzgerald for his help with this project.

\section{References}

Barnes, M., Elliott, L. R., Wright, J., Scharine, A., \& Chen, J. (2019). Robot interaction design research: From teleoperations to humanagent teaming (Technical Report No. ARL-TR-8770). Retrieved from https://apps.dtic.mil/dtic/tr/fulltext/u2/1079789.pdf

Carsten, O. M. J., Lai, F. C. H., Barnard, Y., Jamson, A. H., \& Merat, N. (2012). Control task substitution in semiautomated driving: Does it matter what aspects are automated? Human Factors, 54(5), 747761. doi:https://doi.org/10.1177/0018720812460246

Chen, J. Y. C., \& Barnes, M. J. (2014). Human-agent teaming for multirobot control: A review of human factors issues. IEEE Transactions on Human-Machine Systems, 44(1), 13-29. doi: https://doi.org/10.1109/THMS.2013.2293535

Cooper, A. D., Sterling, C. P., Bacon, M. P., \& Bridgeman, B. (2012). Does action affect perception or memory? Vision Research, 62, 235240. doi:https://doi.org/10.1016/j.visres.2012.04.009

de Visser, E. J., Cohen, M., Freedy, A., \& Parasuraman, R. (2014). A design methodology for trust cue calibration in cognitive agents. In R. Shumaker \& S. Lackey (Eds.), Virtual, augmented and mixed 
reality: Designing and developing virtual and augmented environments (Lecture Notes in Computer Science, Vol. 8525, pp. 251262). Cham, Switzerland: Springer. doi:https://doi.org/10.1007/ 978-3-319-07458-0_24

de Visser, E. J., Pak, R., \& Shaw, T. H. (2018). From "automation" to "autonomy": The importance of trust repair in human-machine interaction. Ergonomics, 61(10), 1409-1427. doi:https://doi.org/10. 1080/00140139.2018.1457725

Durgin, F. H., Baird, J. A., Greenburg, M., Russell, R., Shaughnessy, K., \& Waymouth, S. (2009). Who is being deceived? The experimental demands of wearing a backpack. Psychonomic Bulletin \& Review, 16(5), 964-969. doi:https://doi.org/10.3758/PBR.16.5.964

Durgin, F. H., Klein, B., Spiegal, A., Strawser, C. J., \& Williams, M. (2012). The social psychology of perception experiments: Hills, backpacks, glucose, and the problem of generalizability. Journal of Experimental Psychology: Human Perception and Performance, 38(6), 1582-1595. doi:https://doi.org/10.1371/journal.pone. 0178059

Eves, F. F., Thorpe, S. K. S., Lewis, A., \& Taylor-Covill, G. A. H. (2014). Does perceived steepness deter stair climbing when an alternative is available? Psychonomic Bulletin \& Review, 21(3), 637-644. doi: https://doi.org/10.3758/s13423-013-0535-8

Firestone, C. (2013). How "paternalistic" is spatial perception? Why wearing a heavy backpack doesn't — and couldn't — make hills look steeper. Perspectives on Psychological Science, 8(4), 455-473. doi: https://doi.org/10.1177/1745691613489835

Firestone, C., \& Scholl, B. J. (2014). "Top-down" effects shere none should be found: The El Greco fallacy in perception research. Psychological Science, 25(1), 38-46. doi:https://doi.org/10.1177/ 0956797613485092

Gray, R. (2013). Being selective at the plate: Processing dependence between perceptual variables relates to hitting goals and performance. Journal of Experimental Psychology: Human Perception and Performance, 39(4), 1124-1142. doi:https://doi.org/10.1037/ a0030729

Hancock, P. A., Nourbakhsh, I., \& Stewart, J. (2019). On the future of transportation in an era of automated and autonomous vehicles. Proceedings of the National Academy of Sciences of the United States of America, 116(16), 7684-7691. doi:https://doi.org/10. 1073/pnas.1805770115

Hansen, J. P., Alapetite, A., MacKenzie, I. S., \& Møllenbach, E. (2014). The use of gaze to control drones. Proceedings of the Symposium on Eye Tracking Research and Applications-ETRA' 14, 27-34. doi: https://doi.org/10.1145/2578153.2578156

Janssen, C. P., Donker, S. F., Brumby, D. P., \& Kun, A. L. (2019). History and future of human-automation interaction. International Journal of Human Computer Studies, 131, 99-107. doi:https://doi.org/10. 1016/j.jijhcs.2019.05.006

Jeannerod, M. (1994). The representing brain: Neural correlates of motor intention and imagery. Behavioral and Brain Sciences, 17(2), 187202.

Jeannerod, M. (2001). Neural simulation of action: A unifying mechanism for motor cognition. NeuroImage, 14, 103-109. doi:https://doi. org/10.1006/nimg.2001.0832

Kaber, D. B. (2018). A conceptual framework of autonomous and automated agents. Theoretical Issues in Ergonomics Science, 19(4), 406-430. doi:https://doi.org/10.1080/1463922X.2017.1363314

King, Z. R., Tenhundfeld, N. L., \& Witt, J. K. (2017). What you see and what you are told: An action-specific effect that is unaffected by explicit feedback. Psychological Research, 82(3), 507-519. doi: https://doi.org/10.1007/s00426-017-0848-8

Kirsch, W., \& Kunde, W. (2018). The paddle effect in the Pong task is not due to blocking ability of the observer. Journal of Experimental Psychology: Human Perception and Performance, 44(11), 17991804.
Laitin, E. L., Tymoski, M. J., Tenhundfeld, N. L., \& Witt, J. K. (2019). The uphill battle for action-specific perception. Attention, Perception, \& Psychophysics, 81(3), 778-793. doi:https://doi.org/ 10.3758/s13414-018-01652-w

Lee, J. D., \& See, K. A. (2004). Trust in automation: Designing for appropriate reliance. Human Factors: The Journal of the Human Factors and Ergonomics Society, 46(1), 50-80. doi:https://doi.org/ 10.1518/hfes.46.1.50_30392

Lee, Y., Lee, S., Carello, C., \& Turvey, M. T. (2012). An archer's perceived form scales the "hitableness" of archery targets. Journal of Experimental Psychology: Human Perception and Performance, 38(5), 1125-1131. doi:https://doi.org/10.1037/a0029036

Leyrer, M., Linkenaugery, S. A., Bülthoffz, H. H., Kloosx, U., \& Mohler, B. (2011). The influence of eye height and avatars on egocentric distance estimates in immersive virtual environments. Proceedings of the ACM SIGGRAPH Symposium on Applied Perception in Graphics and Visualization, 67-74. doi:https://doi.org/10.1145/ 2077451.2077464

Linkenauger, S. A., Bülthoff, H. H., \& Mohler, B. J. (2015). Virtual arm's reach influences perceived distances but only after experience reaching. Neuropsychologia, 70, 393-401. doi:https://doi.org/10. 1016/j.neuropsychologia.2014.10.034

Madhavan, P., \& Wiegmann, D. A. (2007). Similarities and differences between human-human and human-automation trust: An integrative review. Theoretical Issues in Ergonomics Science, 8(4), 277301.

Miller, C. A., \& Parasuraman, R. (2007). Designing for flexible interaction between humans and automation: Delegation interfaces for supervisory control. Human Factors: The Journal of the Human Factors and Ergonomics Society, 49(1), 57-75. doi:https://doi.org/ 10.1518/001872007779598037

Moeller, B., Zoppke, H., \& Frings, C. (2016). What a car does to your perception: Distance evaluations differ from within and outside of a car. Psychonomic Bulletin \& Review, 23(3), 781-788. doi:https:// doi.org/10.3758/s13423-015-0954-9

Morgado, N., Gentaz, É., Guinet, É., Osiurak, F., \& Palluel-Germain, R. (2013). Within reach but not so reachable: Obstacles matter in visual perception of distances. Psychonomic Bulletin \& Review, 20(3), 462-467. doi:https://doi.org/10.3758/s13423-012-0358-z

Onnasch, L., Wickens, C. D., Li, H., \& Manzey, D. H. (2014). Human performance consequences of stages and levels of automation: An integrated meta-analysis. Human Factors, 56(3), 476-488. doi: https://doi.org/10.1177/0018720813501549

Open Science Collaboration. (2015). Estimating the reproducibility of psychological science. Science, 349(6251), aac4716-aac4716. doi: https://doi.org/10.1126/science.aac4716

Osiurak, F., Morgado, N., \& Palluel-Germain, R. (2012). Tool use and perceived distance: When unreachable becomes spontaneously reachable. Experimental Brain Research, 218(2), 331-339. doi: https://doi.org/10.1007/s00221-012-3036-5

Parasuraman, R., Sheridan, T. B., \& Wickens, C. D. (2000). A model for types and levels of human interaction with automation. IEEE Transactions on Systems, Man, and Cybernetics, 30(3), 286-297.

Proffitt, D. R. (2006). Embodied perception and the economy of action. Perspectives on Psychological Science, 1(2), 110-122. doi:https:// doi.org/10.1111/j.1745-6916.2006.00008.x

Sebok, A., \& Wickens, C. D. (2017). Implementing lumberjacks and black swans into model-based tools to support human-automation interaction. Human Factors, 59(2), 189-203. doi:https://doi.org/10. 1177/0018720816665201

Sheridan, T. B., \& Verplank, W. L. (1978). Human and computer control of undersea teleoperators. Massachusetts Inst of Tech Cambridge Man-Machine Systems Lab.

Society for Automotive Engineers. (2018). Taxonomy and definitions for terms related to driving automation systems for on-road motor 
vehicles. Retrieved from https://www.sae.org/standards/content/ j3016_201806/

Stefanucci, J. K., Proffitt, D. R., Banton, T., \& Epstein, W. (2005). Distances appear different on hills. Perception and Psychophysics, 67(6), 1052-1060. doi:https://doi.org/10.3758/BF03193631

Stefanucci, J. K., Proffitt, D. R., Clore, G. L., \& Parekh, N. (2008). Skating down a steeper slope: Fear influences the perception of geographical slant. Perception, 37(2), 321-323. doi:https://doi.org/ 10.1068/p5796

Sternberg, S. (1969). The discovery of processing stages: Extensions of Donders' method. Acta Psychologica, 30, 276-315.

Taylor, G. S., Alicia, T. J., Turpin, T., \& Surana, A. (2017). Controlling multiple unmanned aircraft from a manned helicopter: The need for advanced autonomy and refined pilot-vehicle interface. Proceedings of the Human Factors and Ergonomics Society, 61(1), 78-82. doi: https://doi.org/10.1177/1541931213601485

Taylor, G. S., Reinerman-Jones, L. E., Szalma, J. L., Mouloua, M., \& Hancock, P. A. (2013). What to automate: Addressing the multidimensionality of cognitive resources through system design. Journal of Cognitive Engineering and Decision Making, 7(4), 311-329. doi: https://doi.org/10.1177/1555343413495396

Tenhundfeld, N. L., de Visser, E. J., Haring, K. S., Ries, A. J., Finomore, V. S., \& Tossell, C. C. (2019). Calibrating trust in automation through familiarity with the autoparking feature of a Tesla Model X. Journal of Cognitive Engineering and Decision Making, 13(4), 279-294. doi:https://doi.org/10.1177/1555343419869083

Tenhundfeld, N. L., \& Witt, J. K. (2015). The effects of interoceptive attunement on action-specific perception. Visual Cognition, 23(7), 837-840. doi:https://doi.org/10.1080/13506285.2015.1093240

Tenhundfeld, N. L., \& Witt, J. K. (2017). Distances on hills look farther than distances on flat ground: Evidence from converging measures. Attention, Perception, \& Psychophysics, 79(4), 1165-1181. doi: https://doi.org/10.3758/s13414-017-1305-x

Tomzcak, K., Pelter, A., Gutierrez, C., Stretch, T., Hilf, D., Donadio, B., ... Tossell, C. C. (2019). Let Tesla park your Tesla: Driver trust in a semi-automated car. Proceedings of the Annual Systems and Information Engineering Design Symposium (SIEDS) Conference. doi:https://doi.org/10.1109/SIEDS.2019.8735647

Wesp, R., Cichello, P., Gracia, E. B., \& Davis, K. (2004). Observing and engaging in purposeful actions with objects influences estimates of their size. Perception \& Psychophysics, 66(8), 1261-1267. doi: https://doi.org/10.3758/BF03194996

Wickens, C. D. (2018). Automation stages \& levels, 20 years after. Journal of Cognitive Engineering and Decision Making, 12(1), 35-41. doi:https://doi.org/10.1177/1555343417727438

Wiener, E. L., \& Curry, R. E. (1980). Flight-deck automation: Promises and problems. Ergonomics, 23(10), 995-1011.

Witt, J. K. (2011a). Action's effect on perception. Current Directions in Psychological Science, 20(3), 201-206. doi:https://doi.org/10.1177/ 0963721411408770

Witt, J. K. (2011b). Tool use influences perceived shape and perceived parallelism, which serve as indirect measures of perceived distance. Journal of Experimental Psychology: Human Perception and Performance, 37(4), 1148-1156. doi:https://doi.org/10.1037/ a0021933

Witt, J. K. (2015). Awareness is not a necessary characteristic of a perceptual effect: Commentary on Firestone (2013). Perspectives on
Psychological Science, 10(6), 865-872. doi:https://doi.org/10. $1177 / 1745691615598525$

Witt, J. K. (2017). Action potential influences spatial perception: Evidence for genuine top-down effects on perception. Psychonomic Bulletin \& Review, 24(4), 999-1021. doi:https://doi. org/10.3758/s13423-016-1184-5

Witt, J. K., \& Dorsch, T. E. (2009). Kicking to bigger uprights: Field goal kicking performance influences perceived size. Perception, 38(9), 1328-1340. doi:https://doi.org/10.1068/p6325

Witt, J. K., \& Proffitt, D. R. (2005). See the ball, hit the ball: Apparent ball size is correlated with batting average. Psychological Science, 16(12), 937-938. doi:https://doi.org/10.1111/j.1467-9280.2005. 01640.x

Witt, J. K., \& Proffitt, D. R. (2008). Action-specific influences on distance perception: A role for motor simulation. Journal of Experimental Psychology: Human Perception and Performance, 34(6), 1479-1492. doi:https://doi.org/10.1038/cdd.2010.172. MicroRNAs

Witt, J. K., Proffitt, D. R., \& Epstein, W. (2005). Tool use affects perceived distance, but only when you intend to use it. Journal of Experimental Psychology: Human Perception and Performance, 31(5), 880-888. doi:https://doi.org/10.1037/0096-1523.31.5.880

Witt, J. K., Schuck, D. M., \& Taylor, J. E. T. (2011). Action-specific effects underwater. Perception, 40(5), 530-537. doi:https://doi.org/ $10.1068 / \mathrm{p} 6910$

Witt, J. K., South, S. C., \& Sugovic, M. (2014). A perceiver's own abilities influence perception, even when observing others. Psychonomic Bulletin \& Review, 21(2), 384-389. doi:https://doi. org/10.3758/s13423-013-0505-1

Witt, J. K., \& Sugovic, M. (2010). Performance and ease influence perceived speed. Perception, 39(10), 1341-1353. doi:https://doi.org/ $10.1068 /$ p6699

Witt, J. K., \& Sugovic, M. (2013). Spiders appear to move faster than non-threatening objects regardless of one's ability to block them. Acta Psychologica, 143(3), 284-291.

Witt, J. K., Sugovic, M., \& Taylor, J. E. T. (2012). Action-specific effects in a social context: Others' abilities influence perceived speed. Journal of Experimental Psychology: Human Perception and Performance, 38(3), 715-725.

Witt, J. K., Sugovic, M., Tenhundfeld, N. L., \& King, Z. R. (2016). An action-specific effect on perception that avoids all pitfalls. Behavioral and Brain Sciences, 39. doi:https://doi.org/10.1017/ S0140525X15002563

Witt, J. K., Tenhundfeld, N. L., \& Bielak, A. M. (2017). Dissociating perception from judgment in the action-specific effect of blocking ease on perceived speed. Attention, Perception, \& Psychophysics, 79(1), 283-297. doi:https://doi.org/10.3758/s13414-016-1222-4

Witt, J. K., Tenhundfeld, N. L., \& Tymoski, M. J. (2018). Is there a chastity belt on perception? Psychological Science, 29(1). doi: https://doi.org/10.1177/0956797617730892

Wood, G., Vine, S. J., \& Wilson, M. R. (2013). The impact of visual illusions on perception, action planning, and motor performance. Attention, Perception, \& Psychophysics, 75(5), 830-834. doi: https://doi.org/10.3758/s13414-013-0489-y

Publisher's note Springer Nature remains neutral with regard to jurisdictional claims in published maps and institutional affiliations. 